\title{
Molecular Structure of Bis(dimethylsilyl)amine in the Gas Phase
}

\section{Determined by Electron Diffraction}

\author{
GRETE GUNDERSEN * and DAVID W. H. RANKIN **
}

Department of Chemistry, University of Edinburgh, West Mains Road, Edinburgh EH9 3JJ, Scotland

The principal molecular parameters $\left(r_{\mathrm{a}}, \angle_{\mathrm{a}}\right)$ of $\mathrm{NH}\left(\mathrm{SiHMe}_{2}\right)_{2}$ determined by gas-phase electron diffraction are: $\quad r(\mathrm{Si}-\mathrm{N})=172.7(3) \quad \mathrm{pm}$, $r(\mathrm{Si}-\mathrm{C})=186.7(3) \quad \mathrm{pm}, \quad \angle(\mathrm{SiNSi})=130.4(15)^{\circ}$ $\angle(\mathrm{CSiC})=112.8(11)^{\circ}$, and $\angle(\mathrm{NSiC})=110.2(3)^{\circ}$. In the favoured conformation the $\mathrm{SiHMe}_{2}$ groups are twisted $44(5)$ and $16(2)^{\circ}$ from the positions in which the $\mathrm{Si}-\mathrm{H}$ bonds eclipse the $\mathrm{N}-\mathrm{Si}$ bonds, so that the two $\mathrm{SiHMe}_{2}$ groups are staggered when viewed along the $\mathrm{Si} \cdots \mathrm{Si}$ axis. The preference of this form over two other conformations was, however, marginal.

The present investigation is part of a systematic structural and conformational study of methyl derivatives of monosilyl, disilyl and trisilylamines in which we aim to elucidate the bonding conditions in silylamines from complete structural data for this class of compounds. For example, if $d \pi-p \pi$ bonding is a relevant feature of these compounds, its extent should be decreased as more silyl groups are attached to nitrogen with consequent elongation of the silicon-nitrogen bond. Also we aim to study effects of increased methyl substitution within each series of compounds. In this respect the conformation of bis(silyl)amines is of interest in relation to corresponding results for analogous (bis(silyl)ethers: $\mathrm{O}\left(\mathrm{SiH}_{2} \mathrm{Me}\right)_{2},{ }^{1} \mathrm{O}\left(\mathrm{SiHMe}_{2}\right)_{2}$ and $\mathrm{O}\left(\mathrm{SiMe}_{3}\right)_{2}{ }_{2}^{2,3}$ all have preference for conformations which are staggered in the $\mathrm{Si} \cdots \mathrm{Si}$ view. In a recent reinvestigation of $\mathrm{NH}\left(\mathrm{SiMe}_{3}\right)_{2}$ by gas-

\footnotetext{
*Present address, Department of Chemistry, University of Oslo, Oslo 3, Norway.

** Author to whom correspondence should be addressed.
}

phase electron diffraction ${ }^{4}$ the conformation has been determined for the first time and these new results are completely consistent with the results for the ethers. In this paper we give an account of a gas-phase electron-diffraction study of another bis(silyl)amine, $\mathrm{NH}\left(\mathrm{SiHMe}_{2}\right)_{2}$.

\section{EXPERIMENTAL}

A sample of bis(dimethylsilyl)amine was prepared by the gas-phase reaction of ammonia with chlorodimethylsilane: an equivalent preparation using iododimethylsilane has been reported. ${ }^{5}$ It was purified by repeated fractional condensation and its purity was checked by IR spectroscopy.

Electron-diffraction scattering intensities were recorded on Kodak Electron Image plates, using the Edinburgh diffraction apparatus ${ }^{6,7}$ with nozzle-to-plate distances of 128 and $286 \mathrm{~mm}$ and an accelerating voltage of $c a .44 \mathrm{kV}$. During exposures, the sample and the nozzle were maintained at room temperature $(295 \mathrm{~K})$. Data were obtained in digital form using a computercontrolled Joyce-Loebl micro-densitometer with a scanning programme described previously. ${ }^{8}$ Electron wavelengths were determined from the scattering patterns of gaseous benzene, recorded on the same occasions as the sample data.

Calculations were carried out on ICL 2972 computers using established data reduction ${ }^{8}$ and least-squares refinement ${ }^{9}$ programs. Weighting points used in setting up the off-diagonal weight matrices are given together with other pertinent data in Table 1. The molecular-scattering intensities for the two camera distances are shown in Fig. 1 and the corresponding observed radialdistribution curve calculated from the combined 
Table 1. Weighting functions, correlation parameters, and scale factors. ${ }^{a}$

\begin{tabular}{lllllllll}
\hline $\begin{array}{l}\text { Camera } \\
\text { height } \\
\mathrm{mm}\end{array}$ & $\begin{array}{l}\text { Wave- } \\
\text { length } \\
\text { pm }\end{array}$ & $\begin{array}{l}\Delta s \\
\mathrm{~nm}^{-1}\end{array}$ & $s_{\min }$ & $s w_{1}$ & $s w_{2}$ & $s_{\max }$ & $\begin{array}{l}\text { Correlation } \\
\text { parameter }\end{array}$ & $\begin{array}{l}\text { Scale } \\
\text { factor }\end{array}$ \\
\hline 128.4 & 5.677 & 4. & 64. & 70. & 300. & 324. & 0.032 & $0.830(11)$ \\
285.7 & 5.678 & 2. & 20. & 50. & 120. & 142. & 0.041 & $0.867(8)$ \\
\hline
\end{tabular}

${ }^{a}$ See Ref. 9 for an explanation of the symbols.

intensities is shown in Fig. 2. In all calculations the complex scattering factors of Schäfer $e t$. al. were used. ${ }^{10}$

\section{STRUCTURE ANALYSIS}

The final independent parameters used to describe the geometry of the molecule are given
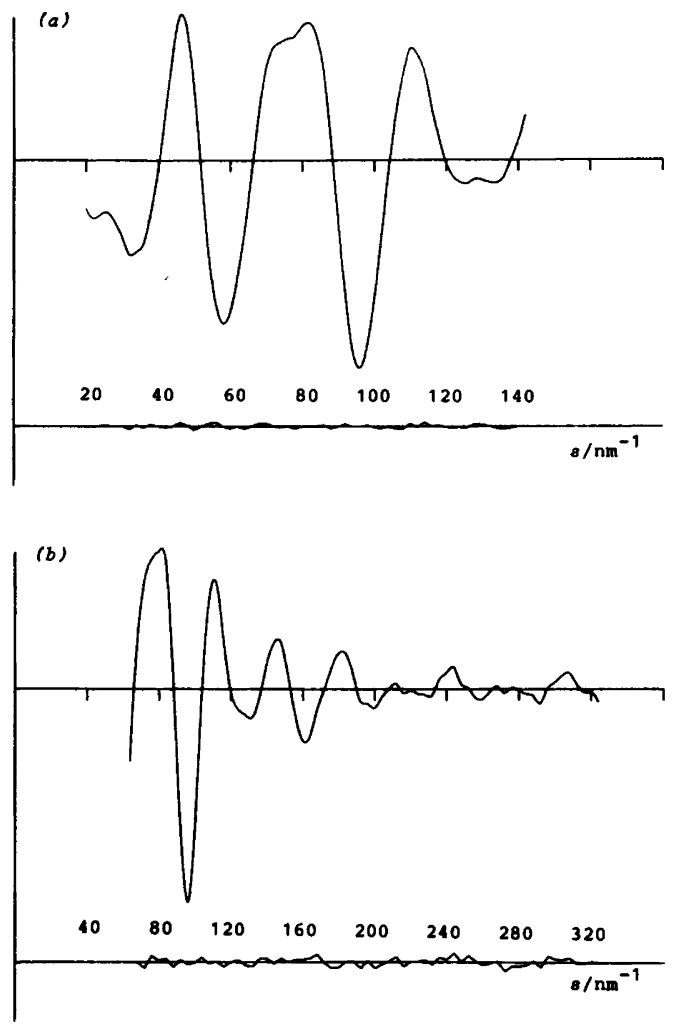

Fig. 1. Experimental molecular scattering intensities for nozzle-to-plate distances of (a) 286 and (b) $128 \mathrm{~mm}$; and the corresponding weighted difference curves obtained using parameter values of Tables 2 and 3 . in Table 2. All torsional (dihedral) angles are defined relative to zero for syn conformations and they are positive for counterclockwise rotation. The atoms of the two $\mathrm{SiHC}_{2}$-groups are numbered as shown in Fig. 3.

Distances involving the amino hydrogen contribute little to the scattering intensity, and the data could not be used to distinguish between planar and non-planar configuration at the nitrogen atom. A planar configuration was adopted by assuming $C_{2 v}$-symmetry for the $\mathrm{HNSi}_{2}$-skeleton. The geometries of the two $\mathrm{R}_{2} \mathrm{HSiN}$-moieties were assumed to be equal except for the torsional orientations about the $\mathrm{Si}-\mathrm{N}$ bonds which were defined by the unique substituent on silicon i.e. by $\phi 1=\phi(\mathrm{H}-\mathrm{Si} 1-\mathrm{N}-\mathrm{Si} 2)$ and $\phi 2=$ $\phi(\mathrm{H}-\mathrm{Si} 2-\mathrm{N}-\mathrm{Si} 1)$ [angles $a 7$ and $a 8$ in Table 2]. The $\mathrm{N}-\mathrm{Si}-\mathrm{H}$ plane was assumed to bisect the $\mathrm{C}-\mathrm{Si}-\mathrm{C}$ angle and the bisector formed an angle with the extension of the $\mathrm{Si}-\mathrm{N}$ bond which was used as an independent parameter [ $a 2$, Table 2] thus making $\angle(\mathrm{N}-\mathrm{Si}-\mathrm{C})$ a dependent angle.

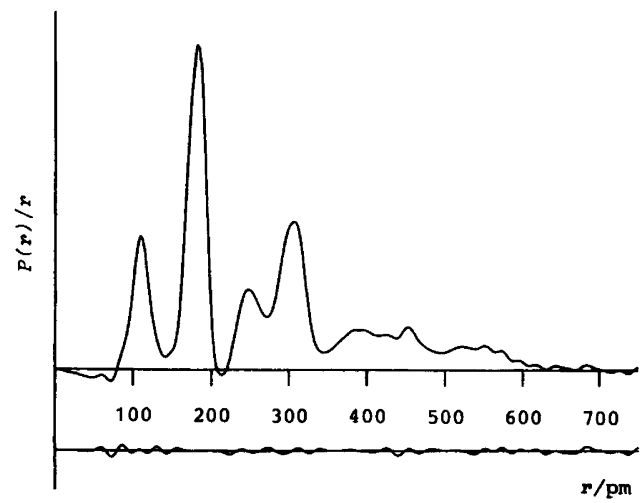

Fig. 2. Experimental and difference radial-distribution curve $P(r) / r$ corresponding to the intensities in Fig. 1. Before Fourier inversion the data were multiplied by $s \cdot \exp \left[\begin{array}{lll}-0.000020 & s^{2}\end{array}\right] /$ $\left(Z_{\mathrm{Si}}-f_{\mathrm{Si}}\right) \cdot\left(Z_{\mathrm{C}}-f_{\mathrm{C}}\right)$. 
Table 2. Molecular parameters. ${ }^{a}$

Indepent distances/pm

$r_{1}(\mathrm{~N}-\mathrm{H})$

$r_{2}(\mathrm{C}-\mathrm{H})$

$r_{3}(\mathrm{Si}-\mathrm{H})$

$r_{4}(\mathrm{Si}-\mathrm{N})$

$r_{5}(\mathrm{Si}-\mathrm{C})$

102.0 (fixed)

111.2(4)

149.0 (fixed)

$172.7(3)$

186.7(3)

Independent angles ${ }^{\circ}$

$a_{1}(\mathrm{SiNSi})$

$a_{2}\left(\mathrm{SiN} / \mathrm{SiC}_{2}\right)^{\mathrm{b}}$

130.4(15)

$51.4(8)$

104.3(20)

$112.8(11)$

111.1(6)

$-18.6(39)$

44.2(45)

$15.6(21)$

$a_{8}(\mathrm{H} 2-\mathrm{Si}-\mathrm{N}-\mathrm{Si})$

+162 .

$-73$.

+133 .

-102 .

Dependent angles ${ }^{\circ}$

$a(\mathrm{NSiC})$

a $(\mathrm{C} 1-\mathrm{Si}-\mathrm{N}-\mathrm{Si})$

$a(\mathrm{C} 3-\mathrm{Si}-\mathrm{N}-\mathrm{Si})$

a(C4-Si-N-Si)

${ }^{a}$ Parameters are $r_{\mathrm{a}}, \angle_{\mathrm{a}}$. Errors quoted in parentheses are estimated standard deviations obtained in least-squares, increased to allow for systematic errors. ${ }^{b}$ See text for explanation. ${ }^{c} a(\mathrm{H}-\mathrm{C} 1-\mathrm{Si}-\mathrm{C} 2)=$ $a(\mathrm{H}-\mathrm{C} 2-\mathrm{Si}-\mathrm{C} 1)$.

The $\mathrm{N}-\mathrm{Si}-\mathrm{H}$ angle was introduced as an independent parameter, but it could be tied to the $a 2$ parameter. Local $C_{3 v}$ symmetry was assumed for the methyl groups and their orientations within the $\mathrm{Si}\left(\mathrm{CH}_{3}\right)_{2}$ groups, were defined by $\theta 1=\theta(\mathrm{H}-\mathrm{C} 1-\mathrm{Si}-\mathrm{C} 2)$ and $\theta 2=\theta(\mathrm{H}-\mathrm{C} 2-\mathrm{Si}-$ $\mathrm{C} 1)$. However, these two parameters were interrelated by one of two relations thus giving only one independent parameter [a6, Table 2]: $\theta 2=\theta 1$ which gives $C_{2}$ symmetry for the $\mathrm{Si}\left(\mathrm{CH}_{3}\right)_{2}$ group; or $\theta 2=60-\theta 1$ which gives a geared arrangement

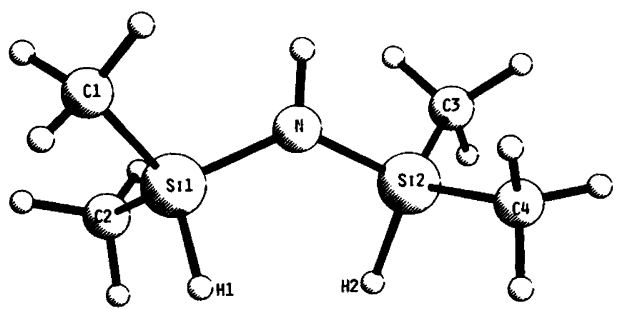

Fig. 3. Perspective view of $\mathrm{NH}\left[\mathrm{SiH}\left(\mathrm{CH}_{3}\right)_{2}\right]_{2}$ corresponding to the results of Table 2 . and coincides with the former model for $\theta 1=30^{\circ}$. The $C_{2}$ model was used in the final refinements [Table 2].

The bond and one-angle distances account for most of the inner part of the radial distribution curve [Fig. 3] which contains four peaks [110, 185,245 and $305 \mathrm{pm}$ ] all of which are composite. Constraints in the structure refinement had to be introduced as indicated in Tables 2 and 3. The interpretation of the outer part of the radialdistribution curve is complicated by the contributions of the many $\mathrm{Si} \cdots \mathrm{H}, \mathrm{N} \cdots \mathrm{H}$ and $\mathrm{C} \cdots \mathrm{H}$ interactions, the distribution of which depends heavily upon the torsional orientations of the four methyl groups. The locations of the $\mathrm{Si} \cdots \mathrm{C}$ and $\mathrm{C} \cdots \mathrm{C}$ distances which determine the overall conformation of the molecule could thus not be determined unambiguously. A systematic search was therefore carried out to find the conformations of the molecule which gave the best fit to the data. Ultimately, after refining the two conformational parameters independently, three different conformations gave good fit to the data. The $\phi 1$ and $\phi 2$ values were: I, 44 and $16^{\circ}$; II, 5 and $194^{\circ}$; and III, 34 and $110^{\circ}$, with $R_{\mathrm{G}^{-}}$-values $4.06,4.57$ and $4.82 \%$, respectively. Views along the $\mathrm{Si} \cdot . \mathrm{Si}$ axes are presented in Fig. 4 . There were no important differences in the skeletal bond distances and valence angles and we have chosen to present the final results as those corresponding to the slightly favoured form (I). They are found in Tables 2-4, and the corresponding weighted difference curve for molecular scattering intensities and the difference radialdistribution curve are shown in Figs. 1 and 2, respectively.

\section{DISCUSSION}

The present investigation yielded three models of $\mathrm{NH}\left(\mathrm{SiHMe}_{2}\right)_{2}$ with excellent agreement to the data. As it was so difficult to distinguish even between these models, the possibility that the vapour contained two or more conformers was not considered in great detail. However, such interpretations are not ruled out and it should be noted that the conformers present may or may not be any of those preferred in the oneconformer interpretation of the data. Preference or rejection of any of the three conformers are marginal. It is noteworthy, however, that the 
Table 3. Interatomic distances and amplitudes. ${ }^{a}$

\begin{tabular}{|c|c|c|c|}
\hline$r_{\mathrm{a}} / \mathrm{pm}$ & $u / \mathrm{pm}$ & & \\
\hline \multicolumn{4}{|c|}{ Torsion independent } \\
\hline $\mathbf{N}-\mathbf{H}$ & 102.0 (fixed) & 8.0 & \multirow{3}{*}{$u 1$} \\
\hline $\mathbf{C}-\mathbf{H}$ & $111.2(4)$ & $7.5(3)$ & \\
\hline $\mathrm{Si}-\mathrm{H}$ & 149.0 (fixed) & 8.3 & \\
\hline $\mathrm{N}-\mathrm{Si}$ & $172.7(3)$ & $5.5(3)\}$ & \multirow{2}{*}{$u 2$} \\
\hline $\mathrm{C}-\mathrm{Si}$ & $186.7(3)$ & $5.8\}$ & \\
\hline $\mathrm{H}(\mathrm{C}) \mathrm{H}$ & 179.8(12) & 11.0 & \multirow{3}{*}{$u 3$} \\
\hline $\mathrm{Si}(\mathrm{C}) \mathrm{H}$ & $249.3(10)$ & $12.9(5)$ & \\
\hline $\mathrm{Si}(\mathrm{N}) \mathrm{H}$ & $234.5(11)$ & 9.0 & \\
\hline $\mathrm{C}(\mathrm{Si}) \mathrm{H}$ & $275.0(19)$ & 10.0 & \multirow{5}{*}{$u 4$} \\
\hline $\mathbf{N}(\mathbf{S i}) \mathbf{H}$ & $254.5(35)$ & 10.0 & \\
\hline $\mathrm{Si}(\mathrm{N}) \mathrm{Si}$ & $313.6(21)$ & $9.5(6))$ & \\
\hline$N(\mathrm{Si}) \mathrm{C}$ & $294.9(9)$ & 7.9 & \\
\hline C(Si)C & $311.1(23)$ & 7.9 & \\
\hline \multicolumn{4}{|c|}{ Torsion dependent } \\
\hline $\mathrm{Si} \cdots \mathrm{C}$ & $448.8(28)$ & $12.6(15)$ & $u 5$ \\
\hline $\mathrm{Si} \cdots \mathrm{C}$ & $423.5(34)$ & $16.6(51)$ & $u 6$ \\
\hline $\mathrm{Si} \cdots \mathrm{C}$ & $462.2(23)$ & 12.6 & $u 5$ \\
\hline $\mathrm{Si} \cdots \mathrm{C}$ & $395.8(53)$ & 16.6 & $u 6$ \\
\hline C...C & $581.8(31)$ & $17.4(49)$ & \\
\hline$C \cdots C$ & $541.5(72)$ & 17.4 & \\
\hline$C \cdots C$ & $486.5(71)$ & 17.4 & ul \\
\hline$C \cdots C$ & $549.1(50)$ & 17.4 & \\
\hline
\end{tabular}

${ }^{a}$ Other $\mathrm{H} \cdots \mathrm{H}, \mathrm{C} \cdots \mathrm{H}, \mathrm{N} \cdots \mathrm{H}$ and $\mathrm{Si} \cdots \mathrm{H}$ distances were included in the refinement, but are not listed here.

Table 4. Least-squares correlation matrix $(\times 100)^{a}$.

\begin{tabular}{|c|c|c|c|c|c|c|c|c|}
\hline & a4 & a5 & a8 & $\mathrm{u} 4$ & u6 & $\mathbf{u} 7$ & k1 & k2 \\
\hline $\begin{array}{l}\text { a1 } \\
\text { a2 } \\
\text { a3 } \\
\text { a5 } \\
\text { a7 } \\
\text { a8 } \\
\text { u1 } \\
\text { k1 }\end{array}$ & -84 & -70 & -63 & -55 & $\begin{array}{r}-65 \\
64\end{array}$ & 74 & $\begin{array}{l}53 \\
62\end{array}$ & $\begin{array}{r}-61 \\
53 \\
66 \\
68\end{array}$ \\
\hline
\end{tabular}

${ }^{a}$ Only elements with absolute values $>50$ are listed.

least favoured model (III, Fig. 4) has one close $\mathrm{C}-\mathrm{Si} \cdots \mathrm{Si}-\mathrm{C}$ angle $\left(18^{\circ}\right)$ whereas both model I and model II are close to staggered in the $\mathrm{Si} \cdots \mathrm{Si}$ view, thus conforming to the preferred conformations of $\mathrm{NH}\left(\mathrm{SiMe}_{3}\right)_{2},{ }^{4} \mathrm{O}\left(\mathrm{SiMe}_{3}\right)_{2}{ }^{3}$ and $\mathrm{O}\left(\mathrm{SiHMe}_{2}\right)_{2} .{ }^{1}$ Moreover, the most favoured conformation (I) is the one most similar to those adopted by the other amines and ethers as it has one narrow and one wide $\mathrm{N}-\mathrm{Si} \cdots \mathrm{Si}-\mathrm{C}$ angle: 24 and $58^{\circ}$ compared to 13 and $37^{\circ} ; 14$ and $46^{\circ}$; and 19 and $41^{\circ}$, respectively, for $\mathrm{NH}\left(\mathrm{SiMe}_{3}\right)_{2}$, $\mathrm{O}\left(\mathrm{SiMe}_{3}\right)_{2}$ and $\mathrm{O}\left(\mathrm{SiHMe}_{2}\right)_{2}$. The conformations of $\mathrm{NH}\left(\mathrm{SiHMe}_{2}\right)_{2}$ and $\mathrm{O}\left(\mathrm{SiHMe}_{2}\right)_{2}$ are not in complete agreement as the latter corresponds to an exchange of $\mathrm{H} 2$ and $\mathrm{C} 4$ in the amine (I, Fig. 4). Very clear conclusions cannot be drawn from 


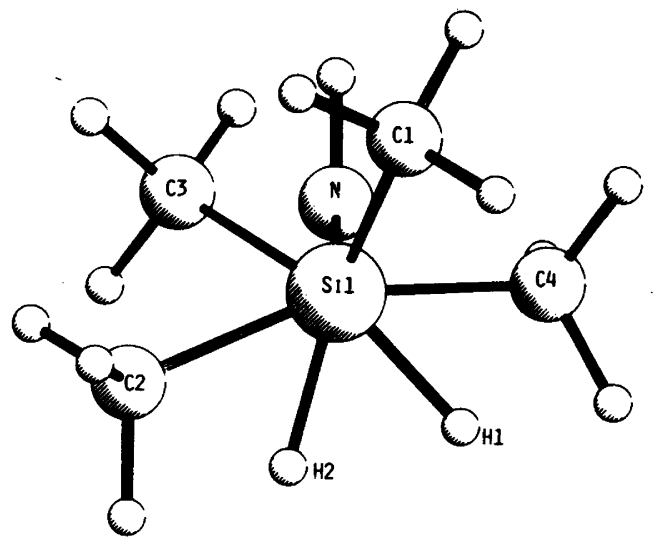


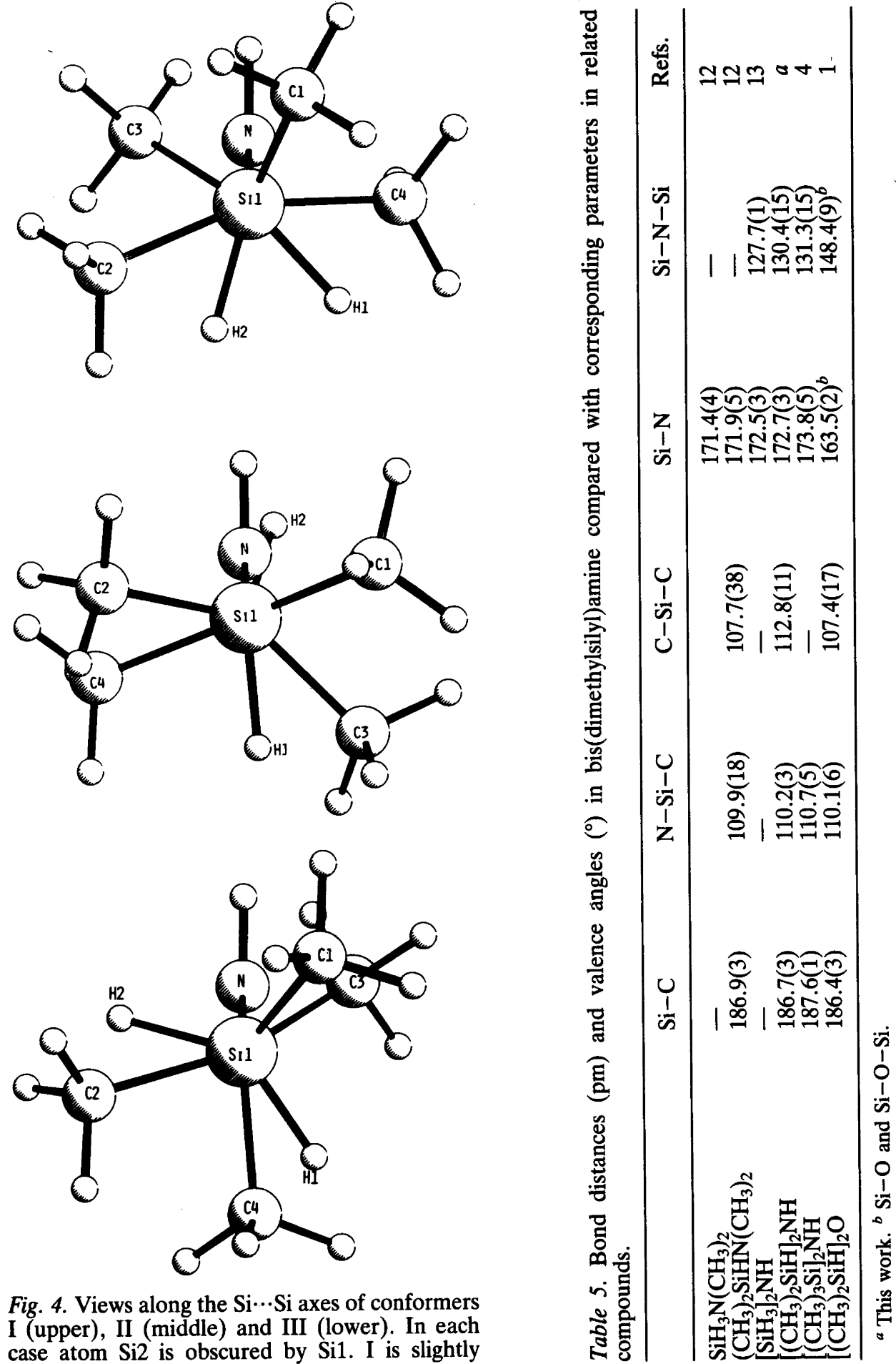

Fig. 4. Views along the $\mathrm{Si} \cdots \mathrm{Si}$ axes of conformers I (upper), II (middle) and III (lower). In each case atom $\mathrm{Si} 2$ is obscured by $\mathrm{Si} 1$. I is slightly favoured over II and III (see text).

Acta Chem. Scand. A 38 (1984) No. 8 
the conformational analysis of $\mathrm{NH}\left(\mathrm{SiHMe}_{2}\right)_{2}$, but it appears that there is some support for the notion that $\mathrm{NH}$ and $\mathrm{O}$ are stereochemically similar, and that the conformation depends mainly on interaction between silicon substituents. This idea is discussed further in a paper on bis(silyl)methylamines. ${ }^{11}$

The skeletal bond distances and valence angles are compared to corresponding parameters of related compounds in Table 5 . It is seen that $r(\mathrm{SiC})$ and the $\mathrm{N}-\mathrm{Si}-\mathrm{C}$ angle are unexceptional There is a widening of the $\mathrm{C}-\mathrm{Si}-\mathrm{C}$ angle relative to the narrow angles [about $107.5^{\circ}$ ] obtained in $\mathrm{Me}_{2} \mathrm{SiHNMe}_{2}{ }^{12}$ and $\left.\mathrm{O}(\mathrm{SiHMe})_{2}\right)_{2}{ }^{1}$ The $\mathrm{C}-\mathrm{Si}-\mathrm{C}$ is negatively correlated to the $\mathrm{Si}-\mathrm{N}-\mathrm{Si}$ angle [Table 4], i.e. for a smaller $\mathrm{C}-\mathrm{Si}-\mathrm{C}$ angle, $\mathrm{Si}-\mathrm{N}-\mathrm{Si}$ would be even wider than $130.4(15)^{\circ}$, which is seen [Table 5] to be intermediate to the angles in $\mathrm{NH}\left(\mathrm{SiH}_{3}\right)_{2}$ and $\mathrm{NH}\left(\mathrm{SiMe}_{3}\right)_{2}$. In the unsubstituted compound the $\mathrm{Si} \cdots \mathrm{Si}$ distance is $309.7 \mathrm{pm}$ and it corresponds closely to the preferred one-angle distance of $310 \mathrm{pm}$ [the non-bonded radii is $\left.155 \mathrm{pm}^{14}\right]$. The increased angles upon methyl substitution correspond to $\mathrm{Si} \cdots \mathrm{Si}$ distances larger than this value [313.6 and $317.0 \mathrm{pm}$, respectively], and therefore probably reflect steric strain introduced by the methyl groups. However, as for the mono(silyl)dimethylamines, ${ }^{12}$ the lengthening of the $\mathrm{Si}-\mathrm{N}$ bond is hardly significant in going from $\mathrm{SiH}_{3}$ to $\mathrm{SiMe}_{2} \mathrm{H}$, but the results for bis(silyl)amines suggest that permethylation of the silyl groups has a greater impact on the bond lengths as both $r(\mathrm{Si}-\mathrm{N})$ and $r(\mathrm{Si}-\mathrm{C})$ are longer in $\mathrm{NH}\left(\mathrm{SiMe}_{3}\right)_{2}$ than in the two less methylated bis(silyl)amines.

The $\mathrm{Si}-\mathrm{N}$ bond appears to be slightly longer [ca. $1 \mathrm{pm}$ ] in the bis(silyl)amines than in the corresponding mono(silyl)amines [Table 5]. This may be attributed to steric strain as the silyl groups are pushed apart. However, this trend is also consistent with decreased $d \pi-p \pi$ bonding as the lone-pair of electrons has to be shared between two $\mathrm{Si}(\mathrm{H} / \mathrm{Me})_{3}$ groups rather than one. A calculated lengthening of the $\mathrm{B}-\mathrm{N}$ bond in bis(boryl)amine compared to that of mono(bory1)amine of about $4 \mathrm{pm}$, which is corroborated by experimental results, has been correlated with both decreased $p \pi-p \pi$ and decrease $\sigma$ bonding. ${ }^{15}$ Thus the slight variation of $r(\mathrm{Si}-\mathrm{N})$ may well be rationalized without introducing effects from $d \pi-p \pi$ bonding.
Acknowledgements. We thank Mr. S. G. D. Henderson for the preparation of the sample and the Science and Engineering Research Council (U.K.) for a research grant.

\section{REFERENCES}

1. Rankin, D. W. H. and Robertson, H. E. J. Chem. Soc. Dalton Trans. (1983) 265.

2. Csákvári, B., Wagner, Zs., Gömöry, P., Mijlhoff, F. C., Rozsondai, B. and Hargittai, I. J. Organomet. Chem. 107 (1976) 287.

3. Barrow, M. J., Ebsworth, E. A. V. and Harding, M. M. Acta Cryst. B 35 (1979) 2093.

4. Fjeldberg, T. J. Mol. Struct. 112 (1984) 159.

5. Ebsworth, E. A. V. and Frankiss, S. G. Trans. Faraday Soc. 63 (1967) 1574.

6. Bauer, S. H. and Kimura, K. J. Phys. Soc. Jpn. 17 (1962) 300.

7. Huntley, C. M., Laurenson, G. S. and Rankin, D. W. H. J. Chem. Soc. Dalton Trans. (1980) 954.

8. Cradock, S., Koprowski, J. and Rankin, D. W. H. J. Mol. Struct. 77 (1981) 113.

9. Boyd, A. S. F., Laurenson, G. S. and Rankin, D. W. H. J. Mol. Struct. 71 (1981) 217.

10. Schäfer, L., Yates, A. C. and Bonham, R. A. J. Chem. Phys. 55 (1971) 3055.

11. Gundersen, G., Rankin, D. W. H. and Robertson, H. E. J. Chem. Soc. Dalton Trans. In press.

12. Gundersen, G., Mayo, R. A. and Rankin, D. W. H. Acta Chem. Scand. 38 (1984) 579.

13. Rankin, D. W. H., Robiette, A. G., Sheldrick, G. M., Sheldrick, W. S., Aylett, B. J., Ellis, I. A. and Monaghan, J. J. J. Chem. Soc. $A$ (1966) 1224.

14. Glidewell, C. Inorg. Chim. Acta 26 (1976) 113.

15. a. Fjeldberg, T., Gundersen, G., Jonvik, T., Seip, H. M. and Sæbø, S. Acta Chem. Scand. A 34 (1980) 547; b. Gundersen, G. Acta Chem. Scand. A 35 (1981) 729.

Received February 14, 1984. 